\title{
DETERMINATION OF THE COEFFICIENT OF FRICTION UNDER COLD TUBE DRAWING USING FEM SIMULATION AND DRAWING FORCE MEASUREMENT
}

\author{
Martin NECPAL, Maroš MARTINKOVIČ, Štefan VÁCLAV \\ SLOVAK UNIVERSITY OF TECHNOLOGY IN BRATISLAVA, \\ FACULTY OF MATERIALS SCIENCE AND TECHNOLOGY IN TRNAVA, \\ INSTITUTE OF PRODUCTION TECHNOLOGIES \\ Ulica JÁnA BotTu 2781/25, 91724 TRNAVA, SLOVAK REPUBliC \\ e-mail: martin.necpal@stuba.sk, maros.martinkovic@stuba.sk, stefan.vaclav@stuba.sk \\ Received: 02.05.2018, Accepted: 29.06.2018, Published: 19.09.2018
}

\begin{abstract}
The purpose of this article is to describe the methodology to define coefficient of friction between a tool and a forming material during tube cold draw technology process. In this regard, an experimental drawing process was done by using the tensile testing machine. The tensile testing machine was modified by additional equipment that allows drawing the tube. During the drawing, the force was recorded. Subsequently, the finite element simulation of cold draw forming was used to generate load-stroke curves with different friction coefficient. The friction coefficient was estimated by comparing the load stroke and the force recorded curves.
\end{abstract}

Key words

Cold forming, friction coefficient, tube drawing, finite element method

\section{INTRODUCTION}

Cold forming is a widely applied process in industrial production. Results of drawing processes are high-quality tubes manufactured under the right economic conditions. To achieve the final diameter and wall thickness, the tubes are reduced successively in several cold drawing steps. Drawing process can be done by drawing the tube through a die and adding a plug, which results in better-defined surface quality. A hot rolled tube is usually used as a feedstock for cold drawing. There are several process variables that influence the success of drawing process. The friction between tools and the forming tube has a great effect on the final shape of the tube and also on the progress of the forming process. Chemical treatment of the tube (pickling, phosphating, lubrication) is made before the drawing process to minimize friction between tools and tube. Finite Element Method (FEM) is one of the most satisfactory approaches to making the forming process superior and forming products of better quality (Neves et al. 2005), (Mar 2017). It is also necessary to know friction coefficient to make a simulation model of the drawing process. Some authors report the friction coefficient value between 0.03 and 0.02 
(Yoshida and Furuya 2004), (Şandru and Camenschi 1988) for simulation. However, for the credibility of the simulation model, it is necessary to identify all parameters. In similar forming technologies, the methods of overlapping the experimental curve and the calibration curves are used (Lăzărescu and Banabic 2017).

\section{MATERIALS AND METHODOLOGY OF EXPERIMENT}

The experimental drawing process was done by using a tensile testing machine. The special equipment was made and connected to the tensile testing machine. The die is attached instead of the adjustable lower crosshead. The experimental tube was drawn through the die. The drawing force is generated by the move of the adjustable upper crosshead. On the upper crosshead, a gripper is fixed, into which the narrowed end of the tube can be attached. During the pipe drawing through the die, the force is recorded. An extensometer was not used during the drawing process. The description of drawing process and adapted tensile testing machine is in Fig. 1.

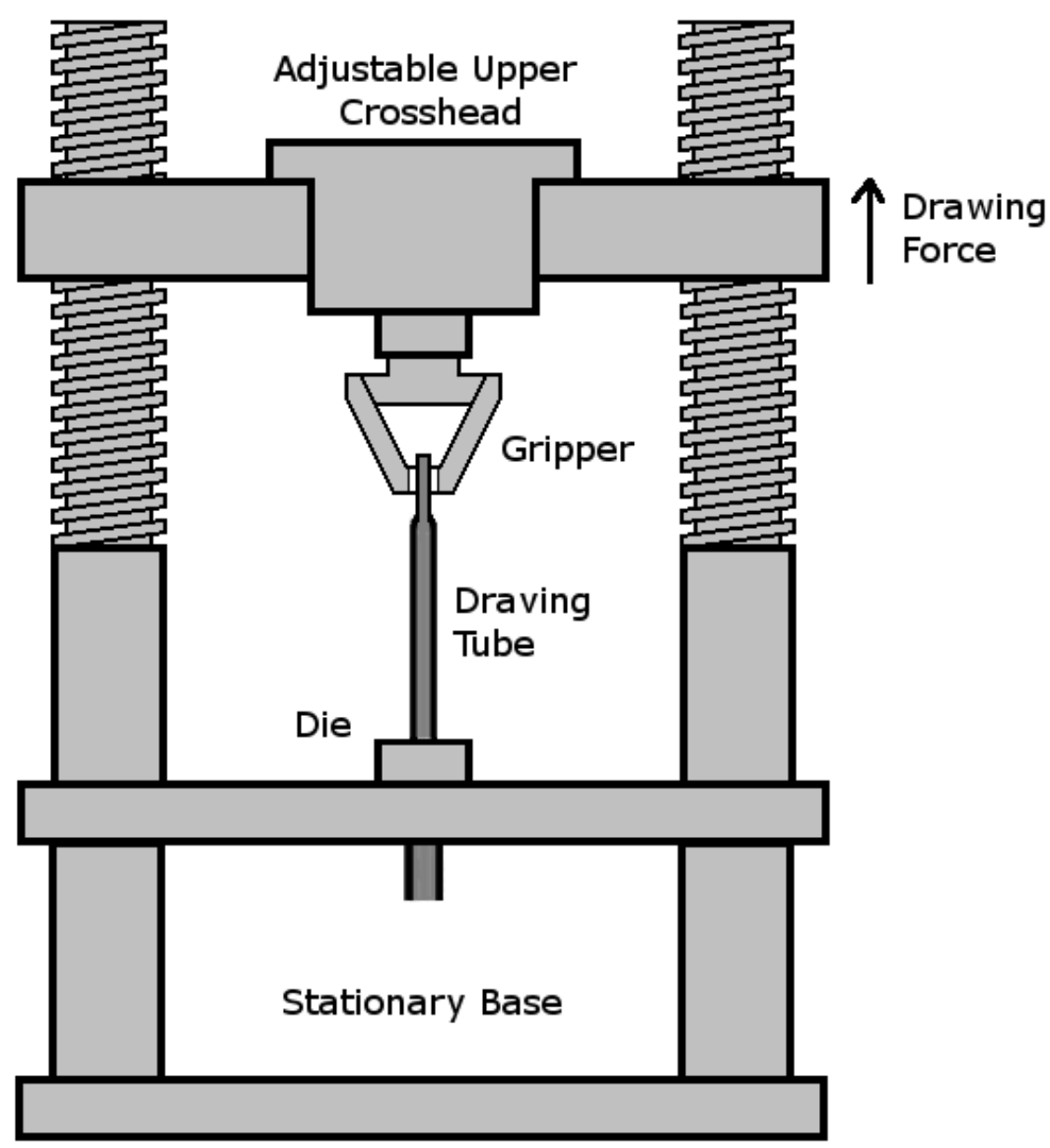

Fig. 1 Drawing process using the tensile testing machine

The electronic equipment of the tensile testing machine allows making drawing force record. The data can be exported as a text file and subsequently used for further analysis. The MATLAB software was used for this purpose.

The dimension of the tube outer diameter was $28 \mathrm{~mm}$ and a wall thickness $4 \mathrm{~mm}$. The material of the tube was SPT360 EN10204/3.1 steel. Four types of dies final diameter of 25mm, length of calibration cylinder $2 \mathrm{~mm}$, the material of sintered carbide and approach angles of $6^{\circ}$, 
$8^{\circ}, 10^{\circ}$ and $12^{\circ}$ were used. As a lubricant, lubricant based plant oil was used. Recorded forces are in Fig. 2.

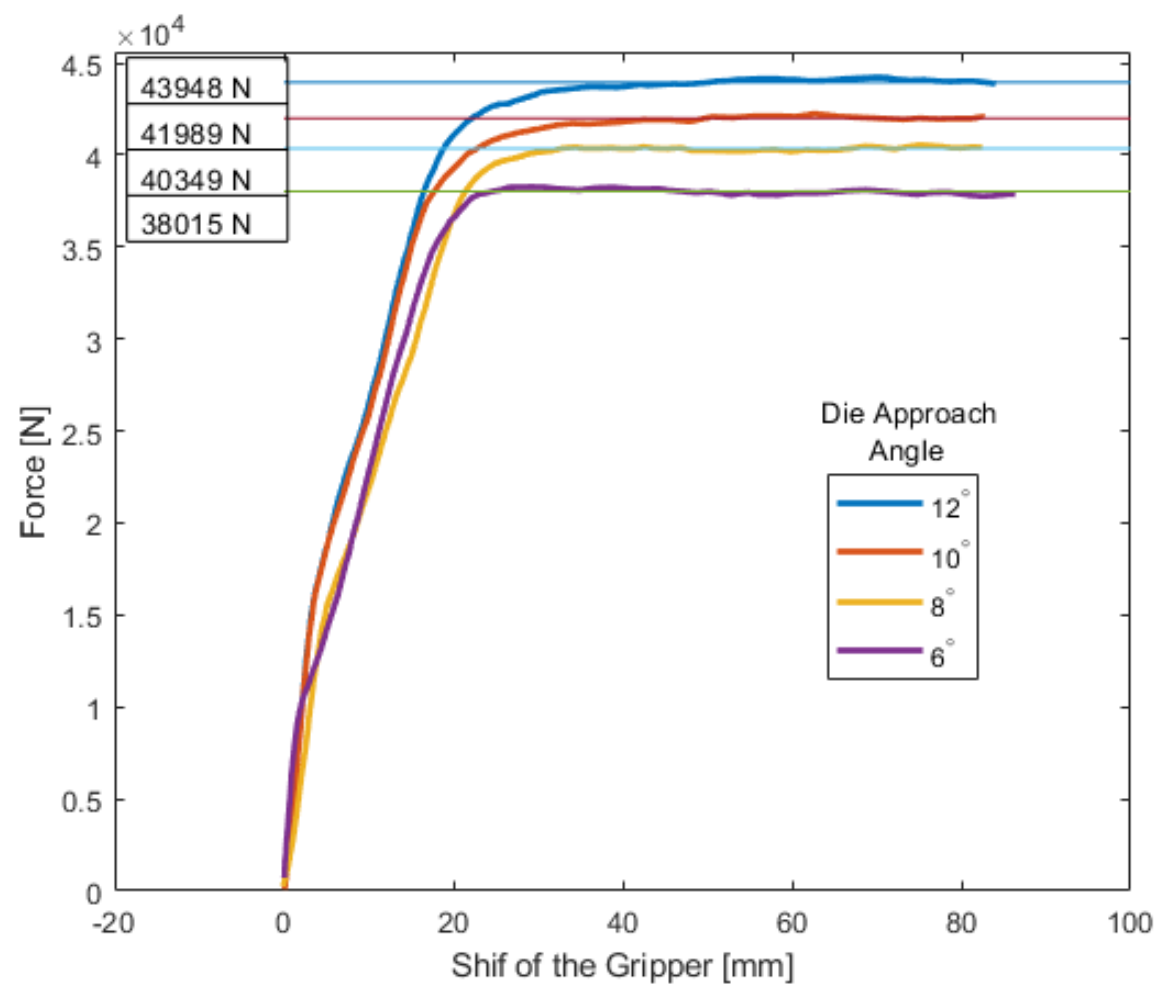

Fig. 2 Drawing process using the tensile testing machine

Initially, the force is zero. Then the force gradually increases, until it is constant and the drawing process is stable. Based on the data of the steady section, the main value of forces was calculated. The most suitable angle for the drawing process appears to be $8^{\circ}$ (Boutenel et al. n.d.). At an angle of $8^{\circ}$, the force $40349 \mathrm{~N}$ was measured. Based on these values of forces, the friction coefficient was determined.

\section{FINITE ELEMENT SIMULATION OF DRAWING PROCESS}

DEFORM 2D and the Lagrangian calculation was set for numerical simulation of cold drawing technology. The initial axisymmetric geometric configuration was set. As the temperature stays lower in cold drawing, the material properties do not vary and can, therefore, be supposed to be independent of the temperature variation.

As the material behavior is considered temperature independent, the power law constitutive equation of the material plastic properties can be used eq. 1 .

$$
\sigma=c \varepsilon^{n} \dot{\varepsilon}^{m}+y
$$

where $\varepsilon$ represents the equivalent of effective plastic strain, $\dot{\varepsilon}$ represents the effective plastic strain rates, and $c, n, m, y$ material parameters are determined by means of tensile test (Holmquist and Johnson 1991)(Majzoobi, Khosroshaki, and Beikmohahhadloo 2009). The $c, n, m, y$ values are listed in Table 1 . As long as strain rate exponent cannot be determined by tensile test, its value is $m=0$. This means the plastic properties of the material are independent of strain rate (Banerjee et al. 2015). 


\begin{tabular}{|c|c|c|}
\hline \multicolumn{3}{|c|}{ Table 1: Mechanical properties of the stainless steel materials } \\
\hline & Material constant (-) & 632.8 \\
\hline$c$ & Strain exponent (-) & 0.1914 \\
\hline$n$ & Strain rate exponent (-) & 0 \\
\hline$m$ & $\begin{array}{c}\text { Initial yield value } \\
(\mathrm{MPa})\end{array}$ & 71.27 \\
\hline
\end{tabular}

The tube material was considered as plastic, the hardening is assumed as isotropic, and yield function type is set as Von Mises. The geometry of the tube was meshed. The eight elements are across the wall of the tube. This mesh of workpiece is sufficient for accuracy and re-meshing procedure during the calculation is not necessary.

The forming tool, (die) was considered as a rigid body. The mesh of tool did not need to be generated for simulation.

The simulation boundary condition of the drawing velocity was $9 \mathrm{~m} \cdot \mathrm{min}^{-1}$. The friction model between the tools and the material was chosen to be a shear-type. Five simulations with a friction coefficient value of $0.2 ; 0.3 ; 0.4 ; 0.5$ and 0.6 were implemented. On the basis of the resulting load stroke values, Fig. 3 expresses linear influence between drawing force and friction coefficient. This influence is expressed in relation [2].

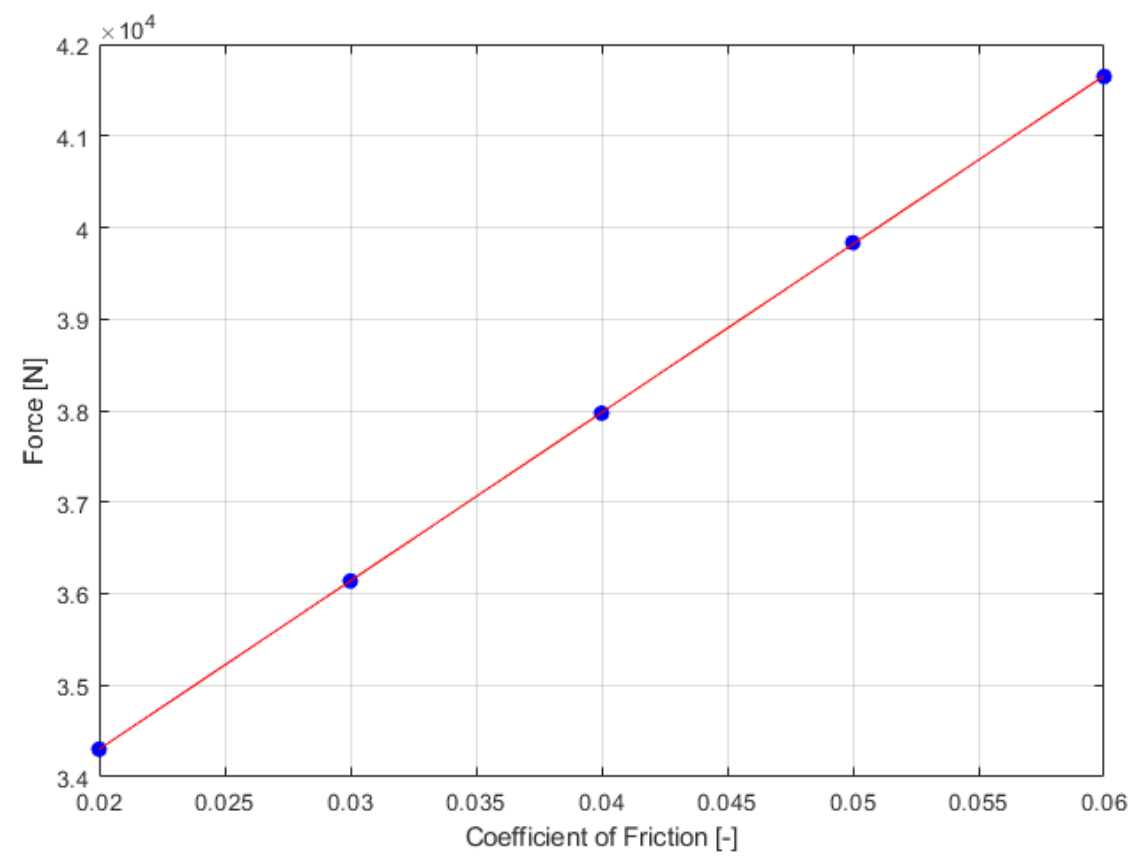

Fig. 3 Influence between drawing force and friction coefficient

$$
\mu=\frac{F-3,062 \cdot 10^{4}}{1,838 \cdot 10^{5}}
$$

For the definition of formula [2], the MATLAB Curve Fitting Toolbox was used with the linear poly setting. The coefficient was fitting with $95 \%$ of confidence bounds. It is possible to calculate any value of friction coefficient of these conditions of the drawing process. If the measured force value is $F=40349 \mathrm{~N}$, the friction coefficient is $\mu=5.26 \cdot 10^{-2}$ using this formula [2]. 


\section{RESULT}

Seven simulations with the friction coefficient $\mu=5,26 \cdot 10^{-2}$ were implemented for seven geometries of dies under different approach angles of $2^{\circ}, 4^{\circ}, 6^{\circ}, 8^{\circ}, 10^{\circ}, 12^{\circ}$ and $14^{\circ}$. As shown in Fig. 4, the angles around $8^{\circ}$ achieved the best load stroke force (Boutenel et al. n.d.).



Fig. 4 Influence between drawing force and Die Approach Angle

\section{CONCLUSION}

The friction coefficient in drawing process was investigated by an experiment using the tensile testing machine and Finite Element Simulation. Based on the result of this experiment and theoretical assumptions, the best angle of drawing tool (Die), is around $8^{\circ}$. Linear influence is between drawing force and friction coefficient. Using the carbide tool and steel workpiece, the friction coefficient is around $\mu=5.26 \cdot 10^{-2}$.

\section{Acknowledgement}

This contribution was supported by the Slovak Research and Development Agency under the contract No. APVV-15-0319 and by the VEGA Grant No. 1/0122/16 of the Grant Agency of the Slovak Republic Ministry of Education.

\section{References:}

1. BANERJEE, A., S. DHAR, S. ACHARYYA, D. DATTA, AND N. NAYAK. 2015. Determination of Johnson Cook Material and Failure Model Constants and Numerical Modelling of Charpy Impact Test of Armour Steel. Materials Science and Engineering: A 640:200-209. Retrieved June 18, 2018 (https://www.sciencedirect.com/science/article/pii/S0921509315300228?via\%3Dihub).

2. BOUTENEL, F., DELHOMME, M., VELAY, V., BOMAN, R. N.D. Finite Element Modelling of Cold Drawing for High Precision Tubes, pp. 1-23. 
3. HOLMQUIST, T., JOHNSON, R. 1991. Determination of Constants and Comparison for Various Constitutive Models. Journal of Physics 4(1), pp. 853-60.

4. LĂZĂRESCU, L., BANABIC, D. 2017. Evaluation of Deep Drawing Force under Different Friction Conditions edited by N. Balc. MATEC Web of Conferences 137:05003. Retrieved (http://www.matec-conferences.org/10.1051/matecconf/201713705003).

5. MAJZOOBI, G. H., KHOSROSHAKI, S., H. BEIKMOHAHHADLOO. 2009. Determination of the Constants of Material Models by Optimization and Numerical Simulation. In: Proc. 9th Int. Conf. on the Mechanical and Physical Behaviour of Materials under Dynamic Loading (DYMAT 2009) (May 2017), pp. 1839-45.

6. MAR, EVA. 2017. Guidelines for Selecting Plugs Used in Thin-Walled Tube Drawing Processes of Metallic Alloys. Metals, 7(12):572. Retrieved (http://www.mdpi.com/2075-4701/7/12/572).

7. NEVES, F. O., BUTTON, S. T., CAMINAGA, C., GENTILE, F. C. 2005. Numerical and Experimental Analysis of Tube Drawing with Fixed Plug. Journal of the Brazilian Society of Mechanical Sciences and Engineering, 27(4), pp. 426-31. Retrieved (http://www.scielo.br/scielo.php?script=sci_arttext\&pid=S1678$58782005000400011 \& \operatorname{lng}=$ en\&nrm=iso\&tlng=en).

8. ŞANDRU, N., CAMENSCHI, G. 1988. A Mathematical Model of the Theory of Tube Drawing with Floating Plug. International Journal of Engineering Science, 26(6), pp. 569-85. Retrieved April 20, 2018 (https://www.sciencedirect.com/science/article/abs/pii/0020722588900559).

9. KAZUNARI, Y., HIROAKI, F. 2004. Mandrel Drawing and Plug Drawing of Shape-MemoryAlloy Fine Tubes Used in Catheters and Stents. Journal of Materials Processing Technology, 153$\begin{array}{llllll}\text { 154(1-3), } & \text { pp. } & 145-50 . & \text { Retrieved } & \text { April }\end{array}$ (https://www.sciencedirect.com/science/article/pii/S0924013604005655?via\%3Dihub).

\section{ORCID:}

Martin Necpal

Maroš Martinkovič

Štefan Václav
0000-0003-2142-9204

$0000-0002-5128-9786$

0000-0003-3266-3645 